\title{
PARTICIPACIÓN COMUNITARIA, DESARROLLO SOSTENIBLE Y ARQUEOLOGÍA: EL CASO DE QUILA QUILA (CHUQUISACA, BOLIVIA)
}

\author{
COMMUNAL PARTICIPATION, SUSTAINABLE DEVELOPMENT AND \\ ARCHAEOLOGY: THE CASE OF QUILA QUILA (CHUQUISACA, BOLIVIA)
}

\author{
María del Pilar Lima Tórrez*
}

\begin{abstract}
Las nuevas leyes bolivianas y las políticas que ellas conllevan han logrado una interesante apertura para la población indígena. En este contexto, el papel de las comunidades dentro de un proyecto arqueológico es cada vez más importante. Su participación ya no se limita a las jornadas de trabajo que las poblaciones locales suelen realizar durante la temporada de campo. En la actualidad se pueden considerar verdaderas contrapartes institucionales para el investigador. Es por esa razón que la arqueología -considerada una ciencia social- asume el rol de generar nuevas políticas de gestión, las cuales posibilitan un diálogo horizontal entre estas poblaciones y los proyectos de investigación. Formas de alentar ese proceso son principalmente: la difusión de la información y la creación de estrategias de sostenibilidad, a través del turismo por ejemplo. Tomando en cuenta este aspecto, es posible plantear que la ciencia arqueológica tiene la capacidad de aportar al desarrollo sostenible local. Un ensayo positivo de esta propuesta es la que se presenta a continuación en el caso específico de Quila Quila, Chuquisaca, Bolivia.
\end{abstract}

Palabras claves: Pueblos indígenas, desarrollo sostenible, turismo.

The new content of Bolivia's laws and politicies provide an interesting aperture to indigenous people. In this context, the community roles within an archaeological project become more important. Participation of local populations is not bound by the daily tasks of field work used to that be done. Actually, the researcher can consider them as truly institutional counterparts. For this reason, Archaeology -considered as a social science-assumes the role of generating new politics, which will allow us to reach a higher level of dialog between indigenous people and researchers. Some of the ways to encourage this process is: to diffuse the archaeological information and creating as strategies of sustainability through tourism. In this way, archaeological science will contribute to local economic development. In this essay a specific case from Quila Quila (Chuquisaca, Bolivia) is presented.

Key words: Indigenous population, sostenibility strategies, tourism.

El reconocimiento oficial de Bolivia como un país pluricultural y multilingüe fue un hecho histórico para todos los bolivianos, pero especialmente para los indígenas. Desde 1953, en que fue aprobado el Voto Universal, surgió la Reforma Agraria y se abolió el pongueaje ${ }^{1}$, la población indígena no había experimentado cambios tan drásticos. Con la modificación del Artículo $1^{\circ}$ de la Constitución Política del Estado en 1994, un nuevo espacio fue ganado por ellos.

Todo este panorama dio paso a la formulación de nuevas leyes, las cuales dan mayor poder de decisión y fiscalización de recursos a la población, además de reglamentar la tenencia de la tierra en el campo. Ya que las más implicadas en ese movimiento fueron las poblaciones indígenas, podría decirse que éstas adquirieron cierto grado de autonomía con respecto al aparato estatal.
Por otro lado, los sistemas económicos tradicionales que giraban principalmente en torno a la agricultura y la minería sufrieron un decaimiento considerable -si no total- en las últimas décadas. En función de estos cambios experimentados en Bolivia durante la década de 1990, la necesidad de nuevas alternativas económicas es creciente. En este contexto, el surgimiento de términos como "desarrollo sostenible" y "sostenibilidad" son el marco de mucha discusión, sobre todo en el área rural.

La idea de lograr un desarrollo sostenible local llevó a explorar nuevas fuentes generadoras de recursos, de las cuales el turismo ofrece las mayores perspectivas. La existencia de profundas tradiciones culturales, festividades religiosas, paisajes geográficos, sitios arqueológicos y artesanía, entre otros, ha hecho de Bolivia un país con bastante potencial turístico. Dicho aspecto es seriamente

* Carrera de Arqueología, Universidad Mayor de San Andrés, La Paz, Bolivia. plimatbo@yahoo.es 
considerado dentro de las políticas de planificación de muchos de los municipios del país.

En ese sentido, este documento abordará el aspecto referido al potencial arqueológico de una región y al aprovechamiento que pueden hacer las organizaciones locales de éste. Para el efecto se presentará un caso muy particular -producto de una experiencia personal- como es el de Quila Quila, Chuquisaca (Lima 1998a, 1998b, 1999). La particularidad de esta región radica en su condición de pueblo indígena y su impulso e interés por el aprovechamiento controlado de sus recursos culturales para su inserción dentro de una estrategia turística. Lo que se espera -a partir de esta experiencia- es mostrar la importancia y el rol que tuvo el conocimiento arqueológico dentro de este proceso.

\section{La Situación de Quila Quila Dentro de la Nueva Legislación Boliviana}

En las últimas dos décadas Bolivia experimentó una serie de cambios políticos debido al gran movimiento que generó el mundo indígena. Como ejemplo, la "Marcha por la Vida y el Territorio" de 1990 se convierte en un hito histórico para las poblaciones indígenas del oriente. A partir de esos acontecimientos una nueva legislación, vinculada especialmente con la titulación de tierras, empezaba a generarse. Producto de ello es la aprobación de la Ley de Modificación del Servicio Nacional de Reforma Agraria (1996) ${ }^{2}$ y del organismo encargado del saneamiento de tierras (Instituto Nacional de Reforma Agraria).

Por otro lado, la formulación de la Ley de Participación Popular (1994) abrió un espacio decisivo para la población en su conjunto. Mediante esta legislación se promovió la participación directa de los municipios en el manejo de los impuestos que recibe el Estado, cosa nunca antes realizada en Bolivia. Es así que la creación de las Organizaciones Territoriales de Base (OTB) -tanto en las ciudades como en el área rural-fue un fenómeno creciente durante esos años. Estas entidades de coparticipación se encargan de fiscalizar el dinero que reciben los municipios.

Sin embargo, no sólo los municipios son captadores de recursos. La legislación mencionada reconoce también los Distritos Indígenas, entidades que reivindican a las poblaciones o naciones originarias $^{3}$ en un territorio determinado, otorgándoles derechos y obligaciones sobre el mismo. Una po- blación originaria puede lograr su declaratoria como Distrito Indígena y obtener su título de Tierra Comunitaria de Origen (TCO). Ello la faculta a administrar y disponer de todos los recursos naturales y culturales dentro de ese espacio, además de custodiar el patrimonio nacional, dentro del cual se contempla el patrimonio arqueológico.

En ese sentido, instituciones estatales como la Dirección Nacional de Arqueología (DINAR) -organismo encargado de la fiscalización de sitios arqueológicos-deben coordinar actividades tanto con los municipios como con las instituciones indígenas. Ese aspecto también es aplicable a los proyectos de investigación arqueológica, los cuales deben negociar -además de obtener el permiso estatalcon dichas instituciones. El mecanismo más utilizado hasta el momento es la firma de convenios de cooperación mutua.

Por otro lado, a partir de la declaratoria de un Distrito Indígena es posible la creación de un municipio y de una OTB para la captación de recursos estatales. Aspectos como éstos han impulsado la reestructuración de entidades indígenas en diferentes partes del país, las cuales reivindican el ayllu y la marka ${ }^{4}$.

La consideración de estos hechos propició también la participación oficial y activa de los habitantes de Quila Quila. A ello pueden sumarse algunos estudios socioculturales que se realizaron en la zona (Klémola 1997; Pacheco et al. 1996). Los resultados de uno de esos estudios plantean que la identidad de esta población pudo estar agregada al ayllu de Kila Kila o distrito de Quila Quila (Klémola 1997:54). En la actualidad, los pobladores de la zona se autorreconocen como indígenas "originarios" 5 pertenecientes al mencionado ayllu, pero también reivindican la existencia de una organización mayor, la Marka Qaraqara ${ }^{6}$; fenómeno que se dio a partir del año 2002 (Juan Gutiérrez comunicación personal 2003). Ninguna de estas entidades cuenta con un reconocimiento oficial por parte del Estado boliviano.

En cuanto al tema administrativo, el problema que enfrenta Quila Quila es que forma parte dependiente del municipio de la ciudad de Sucre, por su cercanía a esta capital. Ese hecho repercute demasiado en el tema de coparticipación, ya que la ciudad capta mayores ingresos en comparación a las poblaciones que la circundan ${ }^{7}$. Esa es la razón por la cual esta "población indígena originaria” está luchando por su declaratoria como Distrito Indí- 
gena (Klémola 1997; Pacheco et al. 1996) para acceder legalmente a los beneficios que ello implica. Los trámites correspondientes son realizados en la ciudad de La Paz desde 1996 con la ayuda de profesionales especializados en el tema (Bubba 1997; Pacheco et al. 1996).

En conocimiento de estos hechos, el entonces Viceministerio de Asuntos Indígenas y Pueblos Originarios (VAIPO) realizó un mapeo del territorio indígena en 1998. Este trabajo hizo posible la construcción de un mapa, el cual verifica los límites territoriales del ayllu Kila Kila (Rodríguez 1999). Dicho mapa fue producto de la reconstrucción oral de las autoridades y ancianos del lugar y no dista mucho de la reconstrucción que se hizo a partir de documentación etnohistórica (Klémola 1997).

En 1996, cuando los originarios de Quila Quila vivían la coyuntura política de una nueva legislación se dio inicio al Proyecto Arqueológico Quila Quila (Lima 1997). Es necesario mencionar que este proyecto contó -desde el comienzo- con el apoyo de toda la población. Las autoridades delegaron a un grupo de personas que participaron durante toda la temporada de campo; podría decirse que dicho grupo representó la contraparte local del proyecto $^{8}$. Con toda seguridad, este gesto se convirtió en el paso inicial y crucial de acercamiento e interacción coparticipativa entre la gente del ayllu y el proyecto.

La dinámica que empezó a generarse en Quila Quila hizo que los investigadores asumieran como una obligación la difusión de información entre la población del ayllu. Sólo hasta ese momento los quilaquileños pudieron evaluar el alcance de las investigaciones arqueológicas, especialmente en lo que se refiere a la revalorización del pasado. Podría decirse que esos acontecimientos despertaron una sensibilización real de la población local hacia los restos arqueológicos.

Esos argumentos fueron utilizados tiempo después para fundamentar su condición de habitantes originarios en ese territorio. En base a la prospección intensiva que se había realizado en la cuenca de Quila Quila en 1996 (Lima 1997), las autoridades originarias impulsaron la realización de un reconocimiento arqueológico general y diagnóstico de todo su espacio (Lima 1998b). El mencionado trabajo tenía el objetivo de mostrar la dimensión de la ocupación prehispánica en este ayllu; esos datos fueron incorporados en el mapa territorial realizado por el VAIPO (Rodríguez 1999).

A pesar de la elaboración de este mapa, la información arqueológica, estudios antropológicos y diagnósticos realizados en la región, Quila Quila hasta ahora no consigue su declaratoria como Distrito Indígena. Ese aspecto está vinculado con la explotación de los depósitos de caliza existentes en la cuenca, recurso que enfrentó a la comunidad con una empresa productora de cemento. Si Quila Quila fuera un Distrito Indígena su población podría ser considerada propietaria de todos los recursos, incluyendo el subsuelo ${ }^{9}$. En vista de que están en juego muchas hectáreas de la mejor caliza para cemento, la gente del ayllu ha visto relegado su trámite.

\section{La Concepción de Desarrollo Sostenible en Quila Quila, un Enfoque Desde la Arqueología}

A pesar de esa suerte de intereses, los originarios de Quila Quila -en función de las experiencias desarrolladas hasta ese momento- fortalecieron su interés por las investigaciones. Los trabajos arqueológicos desarrollados en la cuenca (Lima 1997, 2000) mostraron la importancia que tuvo el área en tiempos prehispánicos. En esta coyuntura fue que en 1998 se "descubrieron" al mundo las milenarias huellas de dinosaurios ${ }^{10}$. Este hallazgo permitió corroborar el potencial de la región también en el ámbito de la Paleontología.

Debido a estos acontecimientos, las autoridades locales y la población en general estuvieron de acuerdo en nombrar un equipo técnico de asesores en Arqueología, Antropología y Paleontología. Este equipo debía encargarse de dar a conocer -a partir de investigaciones- el patrimonio natural y cultural de la zona, además de promover la difusión de información entre los miembros del ayllu.

Siguiendo esa lógica es que fueron organizados el I y II Encuentro de Ayllus Originarios de Quila Quila (1998 y 1999). Estos eventos sólo tuvieron dos versiones, pero en ellos se pudo apreciar toda la riqueza cultural de la región. El equipo de investigación tuvo a su cargo presentaciones sobre temas arqueológicos (Lima 1998a, 1999) y paleontológicos (Federico Anaya comunicación personal 1999), para la población y público en general.

La realización de este tipo de eventos abrió un espacio público de difusión de información técni- 
ca y científica. Sin embargo, su particularidad radicaba en que se trataba de un espacio promovido por los actores locales en donde se hizo evidente la interacción entre investigadores y originarios. Por otro lado, también se notaba el interés de estos últimos de incursionar en el ámbito turístico.

Vale la pena puntualizar que la zona era anteriormente conocida por dos recursos turísticos importantes: los petroglifos del cerro Telapakis y las aguas termales de Talula. Ya los comunarios habían construido algunos refugios a orillas del río Pilcomayo -donde se encuentran las aguas termales- para captar cierto flujo turístico. Este flujo no era muy frecuente; a pesar de eso reportaba algunos ingresos, especialmente referidos a la venta de gaseosas, galletas, comida enlatada, etc. y la entrada a las aguas termales. Las ganancias eran compartidas por toda la población, pues la gente que atendía ese balneario rotaba constantemente y debía rendir informes en sus reuniones periódicas.

Por otro lado estaban los petroglifos del Telapakis, los cuales promovían la afluencia de algunos turistas en ciertas épocas del año. A partir de las investigaciones (Lima 2000), estas muestras del arte rupestre prehispánico de Quila Quila pudieron ser contextualizadas. Esa es la razón por la que surgió la idea de crear un circuito turístico planificado en la cuenca. Dicho circuito debía contemplar los petroglifos, las aguas termales y otros sitios identificados durante la prospección.

Relacionando la idea de una mayor afluencia turística, los comuneros habilitaron un espacio público para la exhibición de artefactos prehispánicos y coloniales ${ }^{11}$. Esta exhibición fue realizada en el II Encuentro de Ayllus Originarios y también contemplaba muestras paleontológicas de la zona. Es así como nació la idea de oficializar un pequeño museo de sitio, promovido y montado totalmente por los originarios de Quila Quila.

La idea de creación de un circuito turístico hizo que se extendiera una invitación oficial, por parte de las autoridades locales, a la Sociedad de Investigación del Arte Rupestre de Bolivia (SIARB). En función de ella se diseñó un plan a mediano plazo para la creación de un parque arqueológico. La implementación de dicho parque tomó en cuenta -inicialmente- un circuito en el área de los grabados rupestres y la construcción de un museo de sitio que contemplara el equipamiento necesario (Lima et al. 1999, Strecker et al. 2000, Taboada 2003).
Este proyecto nació como una idea del ayllu, pero fue apoyado ampliamente por la SIARB, la entonces Dirección Nacional de Arqueología y Antropología (DINAAR) y financiado por el Servicio de Cooperación Social y Técnica Alemana (DED). Hasta la fecha se han cumplido exitosamente tres fases de dicho proyecto. En ese transcurso - como en 1996- la participación de la gente del ayllu y sus autoridades fue decisiva.

Una prueba clara de ello es el movimiento que los quilaquileños protagonizaron en Sucre por la protección de su patrimonio. En septiembre del 2000 los petroglifos del cerro Telapakis sufrieron un grave atentado, hecho que hasta la fecha no ha sido esclarecido. Al parecer, el móvil del mismo era el de deteriorar un atractivo turístico, atentando -como es de suponer- contra el proyecto turístico en la zona.

Con el objetivo de evitar acciones como éstas en el futuro, el mismo año las autoridades originarias contrataron un equipo técnico para la capacitación de guarda-ruinas locales. Las propias autoridades hicieron las gestiones pertinentes para conseguir el financiamiento. Un equipo multidisciplinario tuvo a su cargo la realización de un cursotaller, en el cual veinte comunarios fueron capacitados con mucho éxito (Lima et al. 2000). Con ello se hizo evidente la preocupación de la población local por la protección del patrimonio. Pero más allá de eso, es clara la toma de conciencia y análisis de una realidad que ve en el patrimonio arqueológico una potencial fuente generadora de recursos. Actualmente los originarios de Quila Quila siguen apoyando las labores de la SIARB para la consolidación del parque arqueológico.

\section{Otra Experiencia}

La importancia que adquirieron oficialmente algunos restos del pasado llevó -sobre todo- a la creación de parques arqueológicos. Uno de ellos es el parque arqueológico de Cala Cala, Oruro, declarado Monumento Nacional en 1970. La implementación de la infraestructura está contemplada en un proyecto de coparticipación entre el municipio y la SIARB (Strecker y Taboada 1999). Varias fases de este proyecto fueron financiadas por organismos internacionales y contaron con el aporte de la Alcaldía de Oruro. Durante ese proceso la participación de la población local fue mínima. 
Al contrario de lo que sucede en Chuquisaca, no existe ninguna entidad indígena en Cala Cala; por tanto la contraparte local del proyecto está representada por el municipio de Oruro. Al inicio del mismo se registraron muchas dificultades con los pobladores debido a que una de las actividades más importantes de la zona era afectada por la declaratoria del área como Monumento Nacional. Los calacaleños se dedican al canteo de roca arenisca, desafortunadamente una buena parte de la zona de canteo se ubica en las inmediaciones del parque y hasta la actualidad existe reticencia por abandonar completamente esa actividad y concebir el turismo como una fuente generadora de recursos. Sin embargo, luego de casi cuatro años de trabajo se logró cierta apertura, especialmente a través de cursillos informativos y seminarios de actualización. Ello también posibilitó la realización de investigaciones arqueológicas que permitieran contextualizar el área del parque.

Con esta experiencia se intenta contrastar dos casos que ofrecen perspectivas distintas. Probablemente los factores que marcan esa diferencia están relacionados con el componente poblacional y con la coyuntura política que viven, tanto los originarios de Quila Quila como los pobladores de Cala Cala. Por un lado, para los quilaquileños es importante demostrar la propiedad de su territorio desde tiempos anteriores a la colonia. En el caso de Cala Cala ese aspecto no tiene ninguna relevancia, y más bien se enfatiza en la conservación de una fuente económica como es la zona de canteo. La respuesta a los investigadores está mediada por esas situaciones.

Estos hechos -entonces-podrían estar reflejando que el desarrollo de una región a partir del turismo y con apertura a las investigaciones es producto de una reflexión profunda por parte de los actores locales. Reflexión que contempla tanto el nivel de identificación como el beneficio mediato o inmediato que se pretenda de esas intervenciones. En ese sentido, y a pesar de las anteriores consideraciones, el caso de Quila Quila sigue siendo un ejemplo excepcional de apertura a esta nueva visión.

\section{Conclusiones}

Con el ejemplo de Quila Quila se intentó evidenciar un movimiento indígena consciente del valor de su patrimonio cultural. La revalorización de este movimiento tiene base en el valor que se le está dando al pasado. Al mismo tiempo, muestra la identificación diacrónica de esas culturas con las que actualmente pueblan nuestro territorio.

Sin embargo, el éxito de lograr ese grado de conciencia no radica en el aprovechamiento de circunstancias coyunturales o la implementación de políticas paternalistas. El valor que la gente le da a los restos arqueológicos radica en la identificación que tienen con ellos. Esto significa que el despertar de un compromiso sincero con el pasado de un grupo, étnico o no, necesariamente está vinculado con un movimiento de revalorización. Es posible establecer este compromiso sólo a partir de un diálogo horizontal entre investigadores y actores locales.

De esta forma, esos actores pueden llegar a constituirse en verdaderas contrapartes institucionales, como en el caso de Quila Quila. La finalidad de esta estrategia es la de involucrar a esa gente dentro del quehacer social del arqueólogo y tratar de que ella misma tome las decisiones sobre "su" patrimonio. Aspecto que no excluye, sino fortalece la participación técnica de los arqueólogos.

Es por ello que la difusión de información y la capacitación de gente local juegan un papel de suma importancia, pues posibilitan la toma de conciencia. Si existe un movimiento dinámico de esta información es posible obtener buenos resultados, como se observó también en Cala Cala. Si se diera el caso contrario, es probable que las estrategias utilizadas no hubieran sido las más adecuadas. Esa es la disyuntiva que los arqueólogos tenemos la obligación de considerar en adelante, dentro de una perspectiva más crítica de nuestra propia realidad.

Desarrollo sostenible a través del turismo - una de las opciones más claras a las que apuntan los arqueólogos- es una alternativa interesante como estrategia económica. En términos prácticos eso implica no sólo la recolección de piezas para un museo, sino la generación de una propuesta estratégica y convincente. Para llegar a ese objetivo lo primero que un arqueólogo debería hacer es tomar conciencia de sí mismo y de su labor como investigador social.

Agradecimientos: Esta experiencia no hubiera sido posible de transmitir si no fuera por el apoyo que recibí de los originarios de Quila Quila. Por 
esa razón es que agradezco profundamente a las autoridades del Ayllu de Kila Kila y a todos sus miembros por haberme permitido ingresar en su espacio. Muchas de las reflexiones expresadas en este texto son producto de las conversaciones sostenidas con ellos.

\section{Referencias Citadas}

Bubba, C.

1997 Creación del Distrito Municipal Indígena de los Ayllus de Kila Kila. Informe Final de Consultoría para el Honorable Consejo Municipal de la ciudad de Sucre, Sucre.

Klémola, A.

1997 The Reproduction of Community Through Communal Practices in Kila Kila, Bolivia. Doctoral Dissertation, University of Liverpool, Liverpool.

Lima, P.

1997 Informe Proyecto Quila Quila: Temporada de Prospección. Unidad Nacional de Arqueología, La Paz. Manuscrito en posesión del autor.

1998a La importancia arqueológica de la cuenca de Quila Quila. Ponencia presentada en I Encuentro de Ayllus Originarios de Quila Quila. Chuquisaca.

1998b Reconocimiento extensivo del territorio indígena de los ayllus de Quila Quila, Chuquisaca. Documento interno Ayllus Originarios de Quila Quila. Sucre. Manuscrito en posesión del autor.

1999 Reflexiones sobre el patrimonio arqueológico de Quila Quila. Ponencia presentada en II Encuentro de Ayllus Originarios de Quila Quila. Chuquisaca.

2000 ¿Ocupación Yampara en Quila Quila? Cambios Sociopolíticos de una Sociedad Prehispánica Durante el Horizonte Tardío. Tesis para optar al grado de Licenciatura, Carrera de Arqueología, Universidad Mayor de San Andrés, La Paz.

Lima, P., M. Strecker y F. Taboada

1999 El proyecto "Parque Arqueológico de Quila Quila", Departamento de Chuquisaca. Documento interno, Socie- dad de Investigación del Arte Rupestre de Bolivia, La Paz. Manuscrito en posesión de los autores.

Lima, P., K. Aranda, C. Castillo y A. Macías

2000 Informe de Actividades. I Curso de capacitación para guarda-ruinas locales, Quila Quila, Chuquisaca. Informe interno Ayllus Originarios de Quila Quila, Sucre. Manuscrito en posesión de los autores.

Pacheco, E., M. Herrera, E. Anibarro y A. Herrera

1997 Diagnóstico y planificación participativa del distrito indígena (en trámite). Honorable Alcaldía Municipal de Sucre-Ayllus Originarios de Quila Quila, Sucre. Manuscrito en posesión de los autores.

Rodríguez, L.

1999 Mapa de los Ayllus de Kila Kila. Viceministerio de Asuntos Indígenas y Pueblos Originarios, La Paz. Manuscrito en posesión del autor.

Strecker, M. y F. Taboada

1999 Proyecto Parque Arqueológico-Ecológico de Calacala. Documento interno SIARB, La Paz. Manuscrito en posesión de los autores.

Strecker, M., F. Taboada y P. Lima

2000 Proyecto: Parque Arqueológico de Quila Quila (SIARB - DED - Ayllus de Quila Quila) Informe final de la primera fase. Sociedad de Investigación del Arte Rupestre de Bolivia y Ayllus Originarios de Quila Quila, La PazChuquisaca.

Taboada, F.

2003 Quila Quila, museo de la cultura indígena. Documento interno, Sociedad de Investigación del Arte Rupestre de Bolivia, La Paz. Manuscrito en posesión del autor.

\section{Notas}

1 Sistema en el cual la existencia de los indígenas estaba supeditada a un orden de servilismo a los llamados "patrones". Dentro de ese contexto, el "indio" no tenía un rol activo ni participación directa en las decisiones de la República, ya que no era considerado parte de la población oficial.

2 La ley de Reforma Agraria tiene como principal función el tratamiento de propiedad de tierras, aunque también contempla temas como el arqueológico. En ese marco, se empiezan a implementar los acápites mencionados y uno de ellos es el saneamiento de áreas arqueológicas. El año 2002, con el apoyo del Banco Mundial, se contrató un arqueólogo para la creación de políticas de saneamiento de áreas arqueológicas, además de la generación de políticas de compensación a los pobladores locales.

3 El término "originario" es actualmente muy utilizado para denominar a grupos indígenas, pero al mismo tiempo es bastante discutido a nivel de los pensadores indianistas. Ellos arguyen que dicha terminología también es tomada en un sentido colonialista (Germán Choquehuanca comunicación personal 2001)

4 La reconstitución de entidades, en algunos casos, se basa en mapas poblacionales proporcionados por la etnohistoria. Por ejemplo, varios ayllus del noroeste de Chuquisaca y del norte de Potosí se reunieron para reconstruir el territorio de la Marka Qaraqara, en función de la información etnohistórica que se registra para la zona.

5 En adelante se utilizará este término para hacer alusión a la población local de Quila Quila, la cual se autodefine como 'originaria'.

6 Hasta el año 2002 esta población se reconocía bajo el rótulo de Ayllus Originarios de Quila Quila. Según Juan Gutiérrez, comunicación personal (2003), kuraka de Urinsaya, ahora conforman sólo un ayllu que es parte de una marka mayor.

7 La distribución de los recursos de un municipio está en función del número de habitantes dentro su territorio. Dado 
que Sucre es una ciudad y tiene un área de dispersión definida, es natural pensar que cuenta con el mayor número de habitantes dentro del distrito. Ese hecho incide en que pequeñas poblaciones como Quila Quila reciban menores ingresos y sus necesidades estén supeditadas a las de la ciudad.

8 La participación de estas personas se realizó por turnos y no recibieron pago alguno. Esto se debió a que los kurakas -autoridades originarias máximas- definieron esta participación como obligatoria.

9 La legislación vigente reconoce sólo $0,30 \mathrm{~m}$ de suelo para la propiedad privada. Sin embargo, este principio no puede ser aplicado cuando se trata de poblaciones indígenas reconocidas oficialmente.

10 El farallón "descubierto" representa una de las más espectaculares muestras de fauna extinta. Como es de suponer, el mismo ya era conocido por la población local. Sin embargo su sonada presentación en el ámbito académico causó revuelo, especialmente en Sucre. Actualmente la imagen de los dinosaurios es un símbolo turístico en esa ciudad.

11 Se trataba de artefactos que los habitantes de Quila Quila encontraron en sus parcelas o casas. Se logró que los mismos fueran donados, de esa forma podía darse pie a la construcción de un museo local. 
